\title{
A MORAL NO ENSINO SUPERIOR: PRODUÇÕES CIENTÍFICAS SOBRE DESENVOLVIMENTO MORAL E FORMAÇÃO DE PROFESSORES
}

\section{The moral on higher education: scientific production of moral development and teachers' capacitation}

Maíra de Oliveira Martins - Universidade Estadual Paulista/Brasil. Érica de Cassia Gonçalves - Universidade Estadual Paulista/Brasil.

\begin{abstract}
RESUMO: Este trabalho trata-se de uma pesquisa bibliográfica acerca do desenvolvimento moral na formação de professores. Para isto, pesquisamos os artigos científicos que envolvem o desenvolvimento moral na formação de professores, pois consideramos importante que haja uma preocupação com a formação moral destes, visto que são os agentes mediadores em sala de aula e formadores de crianças em desenvolvimento. Nesta pesquisa, encontramos poucos trabalhos que tratam destes temas de maneira íntima, o que nos leva a pensar que existe muito trabalho a fazer. Isto também se nota a partir das relações existentes nas escolas, os conflitos, e o despreparo do professor para lidar com estas questões. Nos propusemos a investigar as pesquisas relacionadas com esta temática a fim de contribuir para uma reflexão mais ampla, no sentido de como o ensino superior pode formar professores qualificados adequadamente para lidar com questões que extrapolam o campo intelectual; como também, no próprio ensino superior, ultrapassar o campo universitário e pensar o professor atuante, aquele que lida com inúmeros problemas sociais, econômicos e afetivos de seus alunos. Tendo um papel tão importante que é do professor, acreditamos que precisam, e merecem, uma formação mais digna de atuação.
\end{abstract}

Palavras-chave: Capacitação profissional. Desenvolvimento moral. Professores escolares.

ABSTRACT: this work refers itself to a research regarding the moral development on teachers' capacitation. For this, we've searched the scientific articles that approach the moral development on teachers' capacitation, because we believe that's important to have concernings towards professors' capacitation, since they've become mediator agents in class and responsible for the capacitation of children during their graduation. Also, we've found a very few works regarding these themes into a closer approach, taking us to a thought that there's still a lot of work to do in this area. We can also notice the same thing looking to the existing schools' relationships, conflicts, and the unpreparedness of a professor handling these questions. We've purposed ourselves to investigate the researches regarding this theme focusing on the contribution to a bigger and wider reflection, regarding how higher education is capable of graduating professors totally qualifying them to deal with questions that overcome the intelectual field; As also, regarding the very higher education itself, overcoming the college field and thinking on the acting professor, the one who deals with several social, economic and affective problems of their students. Therefore, having this highly important role as a professor, we believe it's needed and deserved, a more worthy of acting capacitation.

Educação, Psicologia e Interfaces, Volume 4, Número 3, p. 1-15, Julho/Setembro, 2020.

ISSN: 2594-5343. DOI: $10.37444 /$ issn-2594-5343.v4i4.286 
KeyWords: Professional Capacitation. Moral Development. School Teachers.

\section{INTRODUÇÃO}

Atualmente, se perguntarmos ao professor "quais são as suas dificuldades em sala de aula?", possivelmente ouviremos "indisciplina", "brigas", "violência". E se perguntarmos “o que faz para solucionar tais problemas?". Possivelmente não saberão o que dizer. Estes fatos ocorrem porque tratar de temas tão complexos que exige uma boa preparação do professor. Os resquícios da educação tradicional em que estamos submetidos precisam ser superados para que os professores estejam preparados para atuar nesses casos, pois, para tal, necessitam de um preparo para as relações morais. Sabe-se que ao contrário, a educação tradicional preocupa-se somente com os conteúdos considerados importantes ao entrar numa sala de aula, com o desenvolvimento de habilidades intelectuais.

Neste sentido, a "culpabilidade" não recai sobre os professores, cujos não sabem lidar com essas situações. Por outro lado, é de responsabilidade deles a formação dos alunos. Então, o que falta na estrutura formadora para que haja esse preparo? Ou melhor, o que é necessário na formação de professores para que estes obtenham sucesso no seu papel profissional? Consideramos que a partir de reflexões sobre as relações poderemos contribuir com a discussão desta problemática.

Ao se falar em relações, estamos diante de vários dilemas, vários pontos de vista, várias opiniões. Mas, de modo geral, uma boa relação implica alguns valores, como o respeito, a justiça, a solidariedade, entre outros. Então, consideramos necessário na formação de professores o desenvolvimento moral, um preparo pessoal do professor, para que este atue segundo a moral, provinda do seu pensamento, da sua afetividade, do seu comportamento. Nesse sentido, pensamos que uma boa estrutura na formação dos professores envolve a questão do seu desenvolvimento moral.

Partindo desta premissa, este artigo tem como finalidade investigar $o$ desenvolvimento moral na formação de professores e quais as possíveis implicações no contexto escolar.

\section{FUNDAMENTAÇÃO TEÓRICA}

Educação, Psicologia e Interfaces, Volume 4, Número 3, p. 1-15, Julho/Setembro, 2020.

ISSN: 2594-5343. DOI: 10.37444/issn-2594-5343.v4i4.286 
A moral no ensino superior: produções científicas sobre desenvolvimento moral e formação de professores

A moral está presente em todos os aspectos da vida social, de maneira a nortear as condutas de todos os indivíduos. Falar sobre moral é falar sobre deveres. A moralidade é fonte de muitas indagações: se há mais de uma moral, qual seus fundamentos, sua legitimidade, sendo o papel da filosofia respondê-los. No entanto, consideramos que a moral também pode ser explorada de maneira científica; procurar entendê-la por meio das condições sociais que a possibilita e até a necessita, como também compreender os processos mentais aos quais legitimem, cabe à Psicologia e à Educação.

Segundo Piaget (1994), a moral é um processo suscetível de evolução. Toda regra é suscetível de se metamorfosear, ou seja, mudar sua forma, a partir de uma diferenciação entre sua qualidade e natureza, num processo de continuidade funcional. Desta forma, a regra metamorfoseada a partir do desenvolvimento da estrutura psicológica tem sua lembrança lá no incio de sua evolução, em que foi alcançando graus sucessivos, entre uma estrutura que sucede a outra. Portanto, podemos reencontrar no adulto regras provindas dos períodos elementares do seu desenvolvimento, o caso da heteronomia e egocentrismo, como também depararmos com crianças apresentando atitudes provindas de estruturas mais desenvolvidas, por exemplo, a cooperação e descentração. O que ocorre é que a diferenciação da natureza das atitudes e crenças apresentam um antagonismo parcial, pois apesar de se tornar mais evidente o egocentrismo e coação na criança e não no adulto, em virtude do seu desenvolvimento estrutural, ambos os fenômenos: egocentrismo e cooperação se encontram tanto na criança como no adulto, pois o espírito é o mesmo. "O adulto todo já está na criança, a criança toda também está no adulto.” (PIAGET, 1994, p. 75). Esta afirmação diz respeito, sobretudo, à psicologia moral.

Deste modo, a metamorfose das regras diz respeito a uma continuidade funcional e distinção de estrutura, o que determinará seu valor intrínseco. No entanto, considerar a unicidade do indivíduo em relação ao desenvolvimento das regras implica a questão da tomada de consciência, que pode resultar na irregularidade entre as atitudes e julgamentos, "o aparecimento de um novo tipo de regras no plano da prática nem [sempre] conduz mais ao aparecimento de uma nova consciência da regra [..]" (PIAGET, 1994, p. 75). As condutas morais nem sempre são retomadas no plano do pensamento no decorrer das ações. Em relação à heteronomia e autonomia, diz o autor, “[...] não poderíamos falar

Educação, Psicologia e Interfaces, Volume 4, Número 3, p. 1-15, Julho/Setembro, 2020.

ISSN: 2594-5343. DOI: 10.37444/issn-2594-5343.v4i4.286 
de estágios gloabais [...], mas apenas de fases [...], definindo um processo que se repete a propósito de cada novo conjunto de regras ou de cada novo plano de consciência ou de reflexão." (PIAGET, 1994, p. 75). Portanto, autonomia e heteronomia constituem-se como tendências, dependendo do contexto a que se aborde.

$\mathrm{Na}$ psicologia infantil, encontramos primeiramente a heteronomia, em virtude, principalmente, da discrepância entre a criança e o meio externo que a rodeia e a educa. A coação do adulto interfere na vida da criança de maneira regressiva e variada ao longo do seu desenvolvimento. Nesse sentido, o respeito unilateral caminha junto com a intervenção do adulto, ao passo que o respeito mútuo vai se estabelecendo pouco a pouco, na medida em que a cooperação vai crescendo nas relações. " [...] a cada nova dosagem da cooperação e da coação, corresponde uma nova qualidade dos estados de consciência e das condutas [...]" (PIAGET, 1994, p. 79). Então, a partir de relações de respeito unilateral, teremos indivíduos em estado moral diferente daqueles em que as relações foram de respeito mútuo.

Portanto, há uma estreita relação entre o respeito unilateral e o egocentrismo. Para Piaget (1994), o egocentrismo constitui-se como uma transição do individual para o social, e no que diz respeito à moral, uma confusão entre a coação e a subjetividade. As regras sociais às quais a criança pequena se submete têm mais significado egocêntrico do que social, pois, ao mesmo tempo que as cumpre, confunde-as com sua fantasia e subjetividade. "O egocentrismo é, ao mesmo tempo, pré social, em relação à cooperação ulterior, e [...] social simplesmente, em relação à coação, da qual constitui, mesmo, o efeito mais direto" (PIAGET, 1994, p. 80). O social entendido por Piaget (1975) se refere à descentração, em virtude das coordenações de pontos de vista. A partir da socialização do pensamento, por meio da linguagem, é possível para a criança coordenar pontos de vista; quando algum fato ou fenômeno ocorre, é a partir dessa coordenação que permite à criança pôr em relação os próprios objetos, dando lugar a uma objetividade nas coisas, em detrimento da própria subjetividade. "A socialização que acompanha o emprego dos signos inseriria o pensamento individual em uma realidade objetiva e comum." (PIAGET, 1975, p. 305). Deste modo, no campo da moral, o egocentrismo é pré social, pois as práticas das regras, mistas entre a coação dos mais velhos e a subjetividade da criança, é menos social que a cooperação, pois esta última implica coordenações de perspectivas e o conhecimento da realidade, tanto lógica quanto moral.

Educação, Psicologia e Interfaces, Volume 4, Número 3, p. 1-15, Julho/Setembro, 2020. ISSN: 2594-5343. DOI: 10.37444/issn-2594-5343.v4i4.286 
A moral no ensino superior: produções científicas sobre desenvolvimento moral e formação de professores

Portanto, a coação do adulto para com a criança e o egocentrismo são aspectos do mesmo fenômeno, heteronomia, não promovendo o desenvolvimento de ambos os processos.

Enquanto a criança não dissocia seu eu das sugestões do mundo físico e do mundo social, não pode cooperar, porque, para tanto, é preciso estar consciente de seu eu e situá-lo em relação ao pensamento comum. Ora, para tornar-se consciente de seu eu, é necessário, exatamente, libertar-se do pensamento e da vontade do outro (PIAGET, 1994, p. 81).

Nas relações recíprocas, ao contrário, há uma estreita relação entre o respeito mútuo e a autonomia da consciência. "[...] o respeito mútuo, bem mais que o respeito unilateral, encontra o elemento de racionalidade anunciado desde a inteligência motora inicial, ultrapassando, assim, o episódio marcado pela intervenção da coação e do egocentrismo" (PIAGET, 1994, p. 82).

O princípio básico que determina o tipo de respeito estabelecido nas relações é o valor ligado a tal respeito. Enquanto na heteronomia o valor corresponde unicamente ao mais velho, superior, na medida em que o 'eu' prevalece unicamente no mundo, o valor do respeito na autonomia consiste em superar o "mais velho", atribuindo uma fronteira entre o 'eu' e o mundo, a partir da cooperação. "Conforme a cooperação substitui a coação, a criança dissocia seu eu do pensamento do outro" (PIAGET, 1994, p. 82). Piaget (1994) considera a cooperação como um atributo do 'eu', não como um egocentrismo infantil, tampouco como um 'eu' egoísta, mas uma personalidade que faz parte de um mundo objetivo, em que se deve respeitar à medida da reciprocidade.

A personalidade é, deste modo, o contrário do eu, o que explica porque o respeito mútuo de duas personalidades, uma pela outra, é um respeito verdadeiro, em lugar de se confundir com o mútuo consentimento de dois "eu" individuais, suscetíveis de ligar parte do mal e parte do bem (PIAGET, 1994, p. 83).

Deste modo, com a cooperação, provinda da personalidade do indivíduo, as regras deixam de ser exteriores. "Tornam-se, ao mesmo tempo, fatores e produtos da personalidade, segundo um processo circular [...]" (PIAGET, 1994, p. 83). É desta maneira que a autonomia supera a heternomia.

Educação, Psicologia e Interfaces, Volume 4, Número 3, p. 1-15, Julho/Setembro, 2020.

ISSN: 2594-5343. DOI: 10.37444 /issn-2594-5343.v4i4.286 
As diferenças entre as relações de respeito unilateral e respeito mútuo consistem em que a primeira impõe regras prontas, inacessíveis, para serem adotadas em bloco, enquanto a segunda supõe uma reciprocidade, em que sua forma de elaborar e cumprir as regras é de controle recíproco, verificado na consciência e discutido no domínio moral.

Então, ao olharmos para a Educação, qual seria o reflexo do desenvolvimento moral em um contexto educacional? As práticas pedagógicas desenvolvidas no âmbito escolar favorecem a autonomia ou reforçam a heterenomia? As relações na escola se baseiam no respeito unilateral ou respeito mútuo? Estes questionamentos nos levam a refletir sobre a formação dos professores, pois, serão estes que atuarão em sistemas educacionais e terão que lidar diariamente com os conflitos, violência, ameaças, agressões físicas ou verbais, bullying, entre outros. A esse respeito, Tognetta e Vinha (2007, p. 10) dizem que

O professor tendo estudado ou não em sua formação o desenvolvimento moral, lá está o professor em sala de aula: sua função ele sabe bem, é educar. E se tal "educação", no que tange ao sentido amplo da palavra, ocupa-se de formar pessoas que respeitem a si e aos outros, sobram justificativas para que haja na escola um trabalho construtivo e sistematizado com regras.

Neste sentido, uma grande missão é conferida aos professores, pois criar condições para que uma criança possa desenvolver a autonomia, respeitar os outros, cooperar, será preciso compreender os mecanismos psicológicos que possibilitam o desenvolvimento moral do sujeito, uma vez que "não adianta tentarmos ensinar a moralidade, pois ela é construída a partir da interação do sujeito com o meio em que vive. É construída por experiências com pessoas e situações" (VINHA, 2000, p. 40)

Um fator essencial é o ambiente sócio moral oferecido à criança, em que Devries e Zan (1998) o definem como construtivista aquele capaz de favorecer o desenvolvimento moral das crianças

Uma atmosfera construtivista sócio moral, na sala de aula, é baseada na atitude de respeito do professor pelos interesses, sentimentos, valores e ideias das crianças. A sala de aula é organizada para satisfazer as necessidades físicas, emocionais e intelectuais das crianças. Ela é organizada para a interação com colegas e para o exercício da responsabilidade infantil. [...] O papel do professor é cooperar com as crianças, tentando compreender seu raciocínio e facilitando o processo construtivo [...] (DEVRIES; ZAN, 1998, p. 87)

Educação, Psicologia e Interfaces, Volume 4, Número 3, p. 1-15, Julho/Setembro, 2020.

ISSN: 2594-5343. DOI: 10.37444/issn-2594-5343.v4i4.286 
A moral no ensino superior: produções científicas sobre desenvolvimento moral e formação de professores

Sendo assim, o ambiente escolar constitui um dos fatores que podem favorecer ou impedir o desenvolvimento da criança, pois de acordo com as autoras, um ambiente cooperativo promove a autonomia, porém, um ambiente coercitivo, reforça a heteronomia. No que diz respeito ao ambiente sócio moral construtivista, este inicia-se pela natureza do relacionamento que o professor estabelece com as crianças, devendo perpassar por um relacionamento cooperativo, no qual se estabelece pela interação social em busca de objetivos comuns entre os indivíduos que consideram-se iguais e tratam uns aos outros assim. Além disso, a interação entre os colegas torna-se essencial para a socialização, trocas de pontos de vistas, "compartilhar e viver em um mundo com os outros." (DEVRIES; ZAN, 1998, p. 60)

Em contraposição, podemos considerar um ambiente tradicional quando este pode ser caracterizado por relações de coerções, autoritarismo, respeito unilateral, interação restrita, em que o adulto é o detentor do conhecimento. Assim, a maior parte das ações são centradas no adulto. Devries e Zan (1998) definem esse ambiente como um local onde o adulto orienta uma moralidade para a obediência; as interações que ocorrem neste ambiente são vistas pelo professor como negativas, pois são geralmente classificadas como "cola" e as sanções são expiatórias, ou seja, não utilizam os conflitos para promover aprendizagens.

Assim, considerando os aspectos psicológicos envolvidos no desenvolvimento moral, compreendemos que não há um indivíduo autônomo ou heterônomo de maneira global. Encontramos tendências de julgamentos e práticas, a partir de sucessivas tomadas de consciência sobre as regras em firmamento. Nesse sentido, é preciso pensar e repensar a moral, ou seja, os deveres, permanentemente, para que se construa e reconstrua as regras aos quais se cumprem. Por isso, afirmamos a necessidade de haver o relacionaciomento com os pensamentos e ações do outro, a fim de tomarmos consciência da realidade, obtendo como resultado o desenvolvimento da cooperação e respeito mútuo; e, portanto, reafirmamos o papel em que o professor exerce sobre o desenvolvimento moral de seus alunos, como promovedores de oportunidades para cooperar e respeitar. Para que ele seja capaz de construir em sua classe um ambiente sócio moral cooperativo, propício ao desenvolvimento moral, é necessário que os educadores recebam uma formação que traz em seu cerne o desenvolvimento moral.

Educação, Psicologia e Interfaces, Volume 4, Número 3, p. 1-15, Julho/Setembro, 2020. ISSN: 2594-5343. DOI: 10.37444/issn-2594-5343.v4i4.286 


\section{CAMINHO DA PESQUISA}

Este trabalho trata-se de uma pesquisa bibliográfica acerca do tema Desenvolvimento Moral na formação dos professores. Para tanto, nos propusemos em apenas pesquisar as produções nas revistas científicas que tratam este tema. Utilizando as palavras-chave "formação de professores" e "desenvolvimento moral", pesquisamos no acervo da plataforma de banco de dados SciELO. Encontramos 9 trabalhos, dos quais 7 abordavam a formação de professores e desenvolvimento moral no sentido de concepções, representações e valores dos professores. Apenas 2 dos artigos encontrados relacionavam o desenvolvimento moral na formação de professores. Estes dois artigos, então, serão apresentados o seu conteúdo.

\section{RESULTADOS E DISCUSSÃO}

O primeiro trabalho encontrado que trata da questão da formação de professores e do desenvolvimento moral é sobre práticas educativas contra a violência escolar, por meio da formação continuada. Gonçalves et. al. (2005) elaboraram um programa de formação continuada para atender às dificuldades que professores estavam enfrentando. De início, os autores indagaram: qual é a percepção dos professores sobre violência? E como lidam com os conflitos cotidianos da escola? Havia discussões a respeito desse tema? Deste modo, "o objetivo deste trabalho é apresentar e discutir os resultados de investigação realizada para compreender as possibilidades e limites de uma experiência de formação continuada" (Gonçalves et. al., 2005). Tratava-se de uma escola de periferia de ensino fundamental, e as principais queixas eram relacionadas à violência. As reuniões eram voltadas para práticas educativas que se poderiam usar em sala de aula para amenizar tais problemas, são elas: a dramatização, a discussão em torno de dilemas morais e dinâmicas de grupo.

Partimos do pressuposto de que a ação educativa que visa à formação para a cidadania e procura favorecer a emergência de interação social construtiva deve estar integrada no cotidiano escolar, de tal forma que o professor seja capaz de aproveitar os múltiplos momentos de conflito

Educação, Psicologia e Interfaces, Volume 4, Número 3, p. 1-15, Julho/Setembro, 2020.

ISSN: 2594-5343. DOI: 10.37444/issn-2594-5343.v4i4.286 
A moral no ensino superior: produções científicas sobre desenvolvimento moral e formação de professores

que surgem na escola para contribuir de forma eficiente para essa formação (GONÇALVES et. al., 2005, p. 638).

Foram utilizados, neste trabalho, diversos referenciais teóricos; e nos que diz respeito à moral, os autores se basearam, principalmente, em Piaget, Kohlberg e Puig (Gonçalves et. al., 2005). A análise das reuniões permitiu aos autores levantarem alguns pontos de reflexão: a) indisciplina e violência dos alunos e falta de motivação; b) dificuldades de mudanças, por motivos de cumprimento de conteúdos curriculares, salas muito cheias e horários rígidos; c) preocupação em orientar os alunos sobre drogas e sexo; d) reconhecimento de que há necessidade de introduzir mudanças nas práticas pedagógicas. Os resultados apresentados pelos professores, por meio das práticas educativas elaboradas na formação continuada, proporcionaram momentos significativos na vida dos adolescentes, denominado momento pedagógico significativo. "Definimos como momentos pedagógicos significativos experiências orientadas pelos professores que oferecem condições para o desenvolvimento da personalidade do aluno" (GONÇALVES et al., 2005, p. 651). Deste modo, os autores consideraram que as ações que propuseram aos professores puderam aliviar algumas tensões de maneira que os adolescentes puderam resolver os problemas competentemente, de forma construtiva.

Os autores concluem que partir da realidade cultural e social da escola, os professores podem recriar meios e técnicas para amenizar e abolir os conflitos entre escolares, adequando-os aos objetivos pedagógicos e construindo novos modelos de relação, desde que haja o compromisso do professor. Neste estudo, Gonçalves et. al. (2005) salienta que os objetivos tiveram êxito pois encontraram nos professores uma "busca incessante de uma escola melhor, que garanta a dignidade do ser humano" (GONÇALVES et al., 2005, p. 657).

Araújo (1996) observa a influência que as relações interpessoais exercem na construção da autonomia dos indivíduos: como as relações autoritárias impedem o desenvolvimento moral dos sujeitos. $\mathrm{O}$ autor ressalta que a heteronomia e a autonomia fazem parte de um processo psicogenético construído pelo indivíduo, uma vez que a construção da moral se inicia na heteronomia e a autonomia a sucede. Deste modo, são condições distintas que se contrapõem, e a tendência é o adormecimento das relações heterônomas. Mas de que modo? Por meio da cooperação. “[...] a cooperação é um processo de relação interpessoal, antes de mais nada, um fator que influencia o

Educação, Psicologia e Interfaces, Volume 4, Número 3, p. 1-15, Julho/Setembro, 2020. ISSN: 2594-5343. DOI: 10.37444 /issn-2594-5343.v4i4.286 
desenvolvimento social, moral, cognitivo e, consequentemente, da personalidade do indivíduo" (ARAÚJO, 1996, p. 107).

O que impede, então, o crescimento dessa tendência à cooperação, e logo a autonomia, são relações autoritárias, em que predominam o respeito unilateral, e bem observado pelo autor, relações estas que se encontram tanto nas escolas como nas famílias. Ao defender a cooperação como fonte de transformações das relações, Araújo (1996) acredita ser a escola um ambiente propício para se cooperar, pois são sujeitos que convivem em condições basicamente iguais, principalmente em questão de idade e nível de conhecimento, onde o prestígio ou autoridade podem ser reduzidos ao máximo. Embora na maioria das escolas atuais não é essa a realidade, Araújo (1996), em suas pesquisas, observou que existe escolas as quais o ambiente é mais propício à cooperação, denominado por ele como ambiente escolar cooperativo.

O que está se chamando de "ambiente escolar cooperativo" não abre mão da figura da autoridade moral e intelectual, não autoritária, do professor como coordenador do processo educacional. O que muda o quadro é que esse professor nem é o que determina tudo dentro da sala de aula e nem deixa que os alunos determinem, porque ele é quem conhece os objetivos pedagógicos. Ele nem estabelece as regras da classe e nem os alunos o fazem sozinhos, porque ele pertence ao grupo e tem maior conhecimento sobre a competência legisladora do grupo [...] (ARAÚJO, 1996, p. 112).

Por mais difícil que seja estabelecer um ambiente cooperativo dentro da escola, mesmo que muitos professores e pais não acreditam nestes pressupostos educacionais, o autor defende esta possibilidade e ressalta

Esse é um dos papéis da ciência dentro do contexto escolar, investigar de forma objetiva as "verdades" que são assumidas por pessoas imbuídas de prestígio e/ou autoridade, e que muitas vezes baseiam-se apenas na tradição, no senso comum ou em interesses pessoais (ARAÚJO, 1996, p. 113).

O segundo trabalho encontrado refere-se às implicações do nível de desenvolvimento moral na Educação Superior. Bordignon (2011) partiu de uma seguinte pergunta: "a partir de que nível e estágio de consciência moral os professores educam seus alunos?" (BORDINGON, 2011, p. 17). Em sua pesquisa adotou o referencial teórico de Kohlberg a respeito do desenvolvimento moral e utilizou seus dilemas morais, 
A moral no ensino superior: produções científicas sobre desenvolvimento moral e formação de professores

formulando a questão: "O que pensa sobre o desenvolvimento moral na Educação Superior? O que faz para o desenvolvimento moral dos seus alunos?" para discutir com 17 professores de uma Instituição de Educação Superior (BORDINGON, 2011, p. 25). Seus resultados indicaram que 5 professores mostraram que seus pensamentos eram voltados para o nível convencional de Kohlberg, concentrando-os no estágio 3; e 6 professores também encontraram-se no nível convencional, mas inclinando suas respostas para o estágio 4. Os outros 6 professores foram categorizados no nível pós convencional, inclinando suas respostas para o estágio 5 do desenvolvimento moral de Kohlberg.

Partindo das pesquisas de Kohlberg, que revelaram que a predominância das pessoas que atingiam o estágio 5 do desenvolvimento moral possuíam educação superior e exerciam uma profissão, Bordingon (2011) levanta a possibilidade de os professores possuírem condições de chegarem ao nível pós convencional, alcançando os estágios 5 e 6. Entretanto, em sua pesquisa, apontou que os professores, de maneira geral, continuam voltados para o nível convencional, preocupando-se com a forma como são vistos pela instituição e sociedade e se estabelecem relações de confiança com seus alunos. Os professores caracterizados no estágio 3, em suas respostas, mostraram preocupar-se com as expectativas dos papéis socialmente elaborados entre os professores, alunos e instituição. "[...] S 12 [...]: 'realizar um processo de autoavaliação com todos os alunos sobre o seu desempenho acadêmico [...], avaliação dos aspectos de presença, interesse, [...] empenho e compromisso como futuro profissional [...]"” (BORDINGON, 2011, p. 24). Os professores do estágio 4 apresentaram respostas também de preocupações com expectativas da profissão, abrangendo a sua consciência. S 7: "respeitar as orientações e normas sobre o andamento da Instituição. [...] Defender as convicções pessoais dentro da visão institucional" (BORDINGON, 2011, p. 24). E os professores classificados no estágio 5 apresentaram seus pensamentos voltados para princípios e valores universalmente aceitos no contrato educativo, como também em direitos individuais da consciência e da liberdade anteriores às orientações normativas da instituição. S 11: “o professor deve pautar-se pelo respeito às individualidades e experiências da vida e cultura que os alunos trazem, ou seja, não podemos impor uma 'moral' aos alunos" (BORDINGON, 2011, p. 25).

Neste sentido, o autor conclui, nesta pesquisa, que a maior parte dos adultos vivem no nível convencional do desenvolvimento moral segundo Kohlberg, ou seja, "a

Educação, Psicologia e Interfaces, Volume 4, Número 3, p. 1-15, Julho/Setembro, 2020.

ISSN: 2594-5343. DOI: 10.37444/issn-2594-5343.v4i4.286 
consciência moral [...] está na conformidade do pensamento e da ação em relação às expectativas e aos papeis socialmente definidos pelo grupo de interesse" (BORDINGON, 2011, p. 20). O grupo de interesse pode ser a religião que se adota, a cultura, e, neste caso, a própria instituição. Deste modo, nas palavras de Bordingon (2011, p. 27)

A reflexão é de que se os professores da educação superior, formadores
de profissionais para a educação básica e superior, se encontram no
nível de desenvolvimento moral convencional, como podem formar
novos professores para a educação moral de crianças e jovens que
possam atingir estágios mais elevados, isto é, do nível baseado em
princípios, onde a consciência moral passa a atribuir um valor moral à
coerência interna da pessoa e aos valores e princípios sociais
internalizados?

“A escola tradicional impõe ao aluno a sua tarefa: ela o 'faz trabalhar"” (PIAGET, 1982, p. 154). Ao dizer isto, Piaget se refere à lógica que está por detraz do "ato de educar". Desta forma, a atividade da educação consiste em permanecer intelectualmente e moralmente o indivíduo na condição de heteronomia, pois está submetida à pressão do professor. Diz Piaget (1982, p. 154) "suscetível, [...] seja de manter-se inconsciente, seja de ser aceita de bom grado". Podemos pensar: no ensino superior é diferente? As escolas não são o reflexo de uma lógica que dita uma formação de formadores?

Tardeli (2013) apresenta um projeto que modificou a estrutura curricular da escola para favorecer a construção da boa convivência na escola. Partindo de uma realidade conhecida por todos a respeito da violência, drogas, desrespeito e conflitos nas escolas, o grupo gestor propôs medidas preventivas dos conflitos para implantar no currículo (TARDELI, 2013). A autora acredita que para se fazer mudanças nas escolas é necessária "a inserção de um trabalho que desenvolva a formação ética dos alunos no currículo da escola" (Tardeli, 2013, p. 167). Neste sentido aponta que atualmente é um desafio "a possibilidade de capacitar adequadamente os professores para que trabalhem nesta direção [...] é, em nossa opinião, a grande meta dos teóricos e pesquisadores da educação" (TARDELI, 2013, p. 168).

A partir dos trabalhos encontrados, podemos perceber um grande desafio no Ensino Superior em promover uma boa estrutura curricular e relacional, capaz de formar professores qualificados para uma visão holística do sujeito. Tendo em vista a literatura levantada, o que se nota é que no ensino superior também prevalece o ensino tradicional, baseado na transmissão de conteúdos, em que, de maneira autoritária, o professor é o

Educação, Psicologia e Interfaces, Volume 4, Número 3, p. 1-15, Julho/Setembro, 2020.

ISSN: 2594-5343. DOI: 10.37444/issn-2594-5343.v4i4.286 
A moral no ensino superior: produções científicas sobre desenvolvimento moral e formação de professores

detentor do saber. Entretanto, no que diz respeito ao desenvolvimento moral, nas produções científicas é possível observar um questionamento quanto à estrutura do ensino superior, bem como levantar alternativas para a construção de professores mais qualificados para lidar com questões morais em sala de aula.

\section{CONSIDERAÇÕES FINAIS}

Em virtude de um empobrecimento das relações humanas em sala de aula, tem-se notado muitos conflitos interpessoais, em que, muitas vezes, o professor é o agente mediador. Nesse sentido, este trabalho teve por objetivo investigar o que se têm produzido a cerca do desenvolvimento moral na formação de professores, a fim de verificar se há preocupações em dar subsídios aos professores em formação, visto que serão formadores de crianças em desenvolvimento.

Deste modo, ao encontrarmos poucos artigos que tratam este tema de maneira bem íntima, consideramos que há um vasto campo de desenvolvimento de pesquisas, pois acreditamos ser de suma importância levantar este tema. Salientamos que talvez existam outros trabalhos, dissertações e teses que abordam o tema em questão; mas deixamos claro que nos limitamos a pesquisar em apenas uma plataforma de dados, que consideramos uma das principais referências em artigos científicos.

Preocupar-se com o desenvolvimento moral na formação de professores, para nós, é uma conduta de sair do ponto de vista dos interesses universitários para atender as necessidades da sociedade; pensar a realidade do professor, aquele dentro da sala de aula, com um número grande de crianças, de periferia, que sofrem vários tipos de violência e repressões, e que, muitas vezes, o professor é o único ponto de referência. Portanto, se seu papel é tão importante para a sociedade, o professor deve ser preparado, também, para as relações sociais, para saber agir e compreender a moral nas situações escolares cotidianas.

\section{REFERÊNCIAS BIBLIOGRÁFICAS}

Educação, Psicologia e Interfaces, Volume 4, Número 3, p. 1-15, Julho/Setembro, 2020. ISSN: 2594-5343. DOI: 10.37444 /issn-2594-5343.v4i4.286 
ARAÚJO, U. F. O Ambiente escolar e o desenvolvimento do juízo moral infantil. In: PIAGET, J., et. al. Cinco estudos de educação moral. Organizador: Lino de Macedo. São Paulo: Casa do Psicólogo, 1996.

BORDIGNON, N. A. Implicações dos níveis de desenvolvimento moral de Kohlberg na educação superior. Revista de Investigación vol. 8. N. I, 2011.

DEVRIES, R \& ZAN, B. A Ética na educação infantil: o ambiente sócio moral na escola. Porto Alegre: Artes Médicas, 1998.

GONÇALVES, M. A. S., et. al. Violência na escola, práticas educativas e formação do professor. Cadernos de pesquisa, vol. 35, n. 126, p. 635-658, set/dez. 2005.

PIAGET, J. A formação do símbolo na criança: imitação, jogo e sonho, imagem e representação. Tradução de Álvaro de Carvalho e Christiano Monteiro Oiticica. $2^{\circ}$ ed. Rio de Janeiro, Zahar, Brasilia, INL, 1975.

Psicologia e Pedagogia. Tradução: Dirceu Accioly Lindoso e Rosa Maria Ribeiro da Silva. $6^{\circ}$ impressão. Rio de Janeiro: Editora Forense, 1982.

O Juízo Moral na Criança. Tradução Elzon Lenardon. São Paulo: Summus, 1994.

TARDELI, D. D. Projeto "Conviver": estabelecendo as relações e organizando o currículo. In: MENIN, M. S. de S., BATAGLIA, P. U. R., ZECHI, J. A. M. (Orgs.). Projetos bem sucedidos de educação em valores: relatos de escolas públicas brasileiras. São Paulo: Cortez, 2013.

TOGNETTA, Luciene Regina Paulino; VINHA, Telma Pileggi. Quando a escola é democrática: um olhar sobre a prática das regras e assembleias na escola. Campinas, SP: Mercado das Letras, 2007

VINHA, Telma Pileggi. O educador e a Moralidade Infantil: uma visão construtivista. Campinas, SP: Mercado das letras; São Paulo: Fapesp, 2000.

\section{Credenciais da/os autora/es}

MARTINS, Maíra de Oliveira. Pesquisadora da Universidade Estadual Paulista UNESP - campus Marília, graduada em Psicologia (UNIMAR), Mestre em Educação (UNESP - Marília). (D) Orcid: https://orcid.org/0000-0002-5674-3482 E-mail:

maira.martins@unesp.br

GONÇALVES, Érica de Cassia. Especialista da Educação - Prefeitura Municipal de Guaxupé/MG, graduada em Pedagogia (CUFEG.), Mestranda em Educação (UNESP Marília). (1) Orcid: https://orcid.org/0000-0002-2511-5387 E-mail:

erica.goncalves.cg@gmail.com 
A moral no ensino superior: produções científicas sobre desenvolvimento moral e formação de professores

Endereço para correspondência: Maíra de Oliveira Martins. Av. Martin Afonso, 87, bl. 1; apto13, Bairro Jardim Monte Castelo, CEP 17522-272 Marília/SP. E-mail: maira.martins@unesp.br

Como citar este artigo (Formato ABNT): MARTINS, Maíra de Oliveira; GONÇALVES, Erica de Cassia. A moral no ensino superior: produções científicas sobre o desenvolvimento moral e formação de professores. Educação, Psicologia e Interfaces, v. 4, n.2, p. 1-15, 2020.

Recebido: $19 / 04 / 2020$.

Aceito: 19/05/2020. 